\title{
ENTRE OMISSÃO E PRECONCEITO RACIAL: discurso-acontecimento
}

\author{
Dalva de Souza Lobo' \\ Marco Antonio Villarta-Neder ${ }^{2}$ \\ Helena Maria Ferreira ${ }^{3}$
}

\section{RESUMO}

O presente artigo tem por objetivo problematizar a proposição/implementação de currículos que abordem as relações étnico-raciais em cursos de professores de língua portuguesa. Nessa direção, a partir de pressupostos epistemológicos do campo bakhtiniano, buscamos defender que a concepção tradicional como um conjunto de disciplinas, conteúdos e atividades não consegue contemplar dimensões que abarquem as interações estabelecidas para que a aprendizagem em uma perspectiva crítica se efetive. Assim, considerando o contexto formativo de um curso de licenciatura em Letras, em que o objeto de estudo é o textoenunciado, uma abordagem discursiva pode favorecer processos de ensinoaprendizagem que impliquem o sujeito e promovam a ressignificação de princípios axiológicos relacionados às questões de raça/racismo. Para a consecução deste trabalho, partimos de uma apresentação de pressupostos epistemológicos defendidos pelo Círculo de Bakhtin, com vistas a evidenciar a relevância de um currículo que contemple uma perspectiva dialógica. Para ilustrar a discussão dos pressupostos epistemológicos, utilizamos alguns excertos de atividades realizadas por alunos de graduação em um curso de extensão que teve por objetivo explorar questões relacionadas à (des)igualdade racial. A partir das discussões empreendidas, procuramos demonstrar que uma formação profissional para a docência demanda não somente a seleção de conteúdos e atividades, mas também, atos responsivos para a constituição de sujeitos éticos e sensíveis às demandas da sociedade.

Palavras-chave: Currículo. Relações étnico-raciais. Círculo de Bakhtin.

\footnotetext{
1 Doutorado em Letras. Universidade Federal de Lavras/MG. Orcid iD: http://orcid.org/00000002-9224-5245. E-mail: dalva.lobo@ufla.br

2 Doutorado em Linguistíca Aplicada. Universidade Federal de Lavras/MG. Departamento de Estudos da Linguagem. Letras. Orcid iD: http://orcid.org/0000-0003-3857-3720. E-mail: villarta.marco@ufla.br

3 Doutorado em Letras. Universidade Federal de Lavras/MG. Departamento de Estudos da Linguagem. Orcid iD: http://orcid.org/0000-0002-8749-5426. E-mail: helenaferreira@ufla.br
} 


\title{
BETWEEN OMISSION AND RACIAL PREJUDICE: event-discourse
}

\begin{abstract}
The present article aims to problematize the proposal / implementation of syllabuses that approach the ethnic-racial relations in courses of Portuguese-speaking teachers. In this direction, from the epistemological assumptions of the Bakhtinian field, we seek to defend that the traditional conception as a set of disciplines, contents and activities can not contemplate dimensions that embrace the established interactions so that learning from a critical perspective becomes effective. Thus, considering the formative context of an undergraduate languages course, where the object of study is the text-enunciated, a discursive approach can favor teaching-learning processes that imply the subject and promote the resignification of axiological principles related to the questions of race / racism. To accomplish this work, we start with a presentation of epistemological assumptions defended by the Bakhtinian Circle, in order to highlight the relevance of a syllabus that contemplates a dialogical perspective. To illustrate the discussion of the epistemological assumptions, we used some excerpts of activities carried out by undergraduate students in an extension course whose purpose was to explore issues related to racial (un) equality. Based on the discussions undertaken, we try to demonstrate that a professional training for teaching demands not only the selection of contents and activities, but also responsive acts to the constitution of ethical students, sensitive to the demands of society.
\end{abstract}

Keywords: Syllabus. Ethnical-racial relations. Bakhtin's Circle.

\section{ENTRE LA OMISIÓN Y PRECONCEPTO RACIAL: discurso-acontecimento}

\section{RESUMEN}

Este artículo tiene como objetivo discutir la proposición / implementación de los planes de estudios que se ocupan de las relaciones étnico-raciales en los cursos de profesor de portugués. En esa dirección, a partir de presupuestos epistemológicos del campo bajtiniano, buscamos defender que la concepción tradicional como un conjunto de disciplinas, contenidos y actividades no logra contemplar dimensiones que abarquen las interacciones establecidas para que el aprendizaje en una perspectiva crítica se efectivice. Así, considerando el contexto formativo de un curso de maestro en Letras, en que el objeto de estudio es el texto enunciado, un abordaje discursivo puede favorecer procesos de enseñanza-aprendizaje que impliquen al sujeto y promuevan la resignificación de principios axiológicos relacionados a las cuestiones de raza / racismo. Para la consecución de este trabajo, partimos de una presentación de presupuestos epistemológicos defendidos por el Círculo de Bajtin, con miras a evidenciar la relevancia de un currículo que contemple una perspectiva dialógica. Para ilustrar la discusión de los supuestos epistemológicos, utilizamos algunos extractos de actividades realizadas por alumnos de graduación en un curso de extensión que tuvo por objetivo explorar cuestiones relacionadas a la (des) igualdad racial. A partir de las discusiones emprendidas, procuramos demostrar que una formación profesional para la docencia demanda no sólo la selección de contenidos y actividades, sino también actos responsivos para la constitución de sujetos éticos y sensibles a las demandas de la sociedad.

Palabras clave: Plan de estudios. Relaciones étnico-raciales. Círculo de Bajtin. 


\section{INTRODUÇÃO}

Tinir de ferros... estalar de açoite... Legiões de homens negros como a noite,

Horrendos a dançar...

Negras mulheres, suspendendo às tetas Magras crianças, cujas bocas pretas Rega o sangue das mães:

Outras moças, mas nuas e espantadas, No turbilhão de espectros arrastadas,

Em ânsia e mágoa vãs! E ri-se a orquestra irônica, estridente... E da ronda fantástica a serpente Faz doudas espirais ... Se o velho arqueja, se no chão resvala, Ouvem-se gritos... o chicote estala. E voam mais e mais... Presa nos elos de uma só cadeia, A multidão faminta cambaleia, E chora e dança ali! Um de raiva delira, outro enlouquece, Outro, que martírios embrutece,

Cantando, geme e ri! Existe um povo que a bandeira empresta P'ra cobrir tanta infâmia e cobardia!...

E deixa-a transformar-se nessa festa

Em manto impuro de bacante fria!... Meu Deus! meu Deus! mas que bandeira é esta,

Que impudente na gávea tripudia?

(CASTRO ALVES, O Navio Negreiro, 1869)

No antagonismo entre a poeticidade e as impactantes escolhas lexicais constantes do poema de Castro Alves, iniciamos nosso exercício de escrita. Destacamos que esse antagonismo também se evidencia no cotidiano social, em que há um discurso de igualdade entre as pessoas, mas há também uma per/insistência de atitudes de preconceitos que acabam por perpetrar/perpetuar tendências de dominação étnica consolidadas, constituindo-se, também, como dominação ideológica e política.

Partimos do pressuposto de que a minimização de atitudes antirracistas demanda um esforço coletivo de enfrentamento de comportamentos de preconceito e de discriminação que perpassam as relações humanas. Iniciativas para esse enfrentamento já foram implementadas, como a lei 
10.639, de 20034, que torna obrigatório o ensino da história e cultura afrobrasileira nas escolas, visando a resgatar a presença do negro e as suas contribuições para a constituição social, econômica e política da história brasileira.

Considerando a referida lei e o poema de Castro Alves, datado de 1869, publicado no século XIX, algumas questões que se nos colocam como relevantes para reflexão são: em que medida os currículos tematizam discussões que ancoram construções/práticas discursivas sobre raça/etnia e problematizam as representações sociais? Que bases epistemológicoaxiológicas podem sustentar uma proposição de um currículo que efetivamente contribua para a formação de professores de línguas? Como os sujeitos-futuros professores se constituem a partir e por meio dos currículos? Como implicar sujeitos-futuros professores de línguas para um trabalho com as relações étnico-raciais?

Essas são algumas das indagações que, como docentes de um curso de licenciatura em Letras, nos motivaram a desenvolver uma reflexão sobre a relevância atribuída ao currículo no âmbito de uma formação docente reflexiva. Ressaltamos, aqui, que concebemos o currículo não apenas como um conjunto das disciplinas, conteúdos e referências propostos para um curso de graduação, mas também como o conjunto de bases epistemológico-axiológicas que fundamentam as inter-ações estabelecidas no percurso formativo.

Nesse sentido, este artigo não tem a pretensão de delinear uma trajetória histórica da chegada do negro ao país, nem empreender uma interpretação exaustiva dos efeitos da Lei 10.639, de 2003, mas nos limites da proposta desta reflexão, problematizar o lugar das discussões sobre as questões étnico-raciais nos currículos voltados para a formação de professores de línguas.

\footnotetext{
${ }^{4}$ Nos estabelecimentos de ensino fundamental e médio, oficiais e particulares, torna-se obrigatório o ensino sobre História e Cultura Afro-Brasileira. O conteúdo programático a que se refere o caput deste artigo incluirá o estudo da História da África e dos Africanos, a luta dos negros no Brasil, a cultura negra brasileira e o negro na formação da sociedade nacional, resgatando a contribuição do povo negro nas áreas social, econômica e política pertinentes à História do Brasil (BRASIL, 10.639, 2003).
} 
Segundo Villarta-Neder, Ferreira e Ribeiro (2018, p. 56),

\begin{abstract}
Ao atentarmos para problematizações e discussões em ambientes escolares acerca de questões referentes às relações que englobam raça ou etnia, verificamos que ainda existe uma lacuna a ser preenchida, pois o tratamento dispensado às referidas questões nesses espaços ainda se restringe às datas comemorativas mediante a exigência do cumprimento do calendário escolar, camuflando uma situação de inserção dessa temática no currículo. Desse modo, mobiliza-se para uma ação pedagógica que parece não trazer resultados profícuos para a formação de cidadãos, o que implica na promoção, na consolidação e na perpetuação de discursos étniconormativos na sociedade.
\end{abstract}

É sabido que as universidades são obrigatoriamente demandadas a incorporarem em seus currículos a educação das relações étnico-raciais e ao ensino de história e cultura afro-brasileira e africana ${ }^{5}$. Mas não basta a inserção da temática no currículo, é preciso refletir sobre os efeitos dessa inserção. No âmbito escolar, são bastante recorrentes atitudes de bulliyng, mas a questão é mais ampla: é preciso enfrentar ideologias eugenistas e de branqueamento, que constituem violência física e simbólicab.

Compreender alguns dos elementos que marcam a fronteira entre a omissão e o posicionamento crítico pode favorecer subsídios para uma atuação pedagógica mais reflexiva. Essa questão poderá trazer contribuições para a proposição de atividades curriculares, que efetivamente integrem as questões raciais no bojo das discussões, notadamente, em cursos de licenciatura em Letras, em que há uma

\footnotetext{
${ }^{5}$ De acordo com o Instrumento de Avaliação de Cursos de Graduação presencial e a distância (BRASIL, 2017), é obrigatória a abordagem de conteúdos curriculares que promovam o efetivo desenvolvimento do perfil profissional do egresso em relação às políticas de educação das relações étnico-raciais e o ensino de história e cultura afrobrasileira, africana e indígena.

(http://download.inep.gov.br/educacao_superior/avaliacao_cursos_graduacao/instrument os/2017/curso_reconhecimento.pdf)

${ }^{6}$ Para tal, as universidades possuem previsão legal para a organização curricular que pode ter parte da carga horária destinada para discussões de temáticas sociais, a saber: prática como componente curricular, com 400 (quatrocentas) horas distribuídas ao longo do processo formativo (BRASIL, Resolução n.1 de 07/2015); curricularização das atividades de extensão nos cursos de graduação, com $10 \%$ (dez) da carga horária total do curso (BRASIL, Lei $n^{\circ}$ 13.005, de junho de 2014),com atribuição de créditos específicos para a inserção de temáticas sociais e atividades complementares, com 200 (duzentas) horas (BRASIL, Resolução n.1 de 07/2015), com atividades teórico-práticas de aprofundamento em áreas específicas de interesse dos estudantes, entre elas, a diversidade étnico-racial.
} 
demanda por (des)construção de discursos, veiculados nos textos que circulam na sociedade. Nesse contexto, a formação deve preparar o futuro professor não somente para a proposição de atividades de compreensão/interpretação de textos, mas para uma abordagem que permita conceber o texto como enunciado7, ou seja, como uma prática social.

Ao tomarmos como ponto de partida o excerto do poema de Castro Alves, buscamos demonstrar que os discursos são produzidos em um determinado tempo-espaço8, trazendo representações e construções discursivas relevantes para a constituição dos sentidos e das (inter)subjetividades.

Nesse contexto, a proposta deste artigo se direciona para uma análise das bases epistemológico-axiológicas que podem (re)significar a proposição/implementação de um currículo voltado para a formação de professores de línguas, à luz de Bakhtin e de seus seguidores.

Com vistas a ilustrar a discussão, utilizamos excertos de respostas de participantes de um curso de extensão, ofertado para licenciandos do curso de Letras. O referido curso contemplou uma proposta de problematização

\footnotetext{
7 O texto-enunciado, segundo Bakhtin (1979 [2011], em sua constituição, apresenta dois polos: a) texto como sistema, compreendido como forma, estrutura linguística, organizada dentro de um sistema universalmente aceito; b) texto como enunciado, que corresponde ao seu plano discursivo, portanto, mais amplo, uma vez que extrapola-se para 0 extralinguístico, envolvendo o contexto sócio-histórico e ideológico da situação de produção e, portanto, ligado às relações dialógicas que são peculiares à situação discursiva (ROSA, COSTA-HÜBES, 2015, p. 147). Para o autor russo, os textos merecem análise somente se considerados enquanto enunciados, já que, para ele, o "acontecimento da vida do texto, isto é, sua verdadeira essência, sempre se desenvolve na fronteira de duas consciências, de dois sujeitos." (BAKHTIN, 2011, p. 311).

8 Analisar as relações étnico-raciais demandam um olhar para a constituição histórica da sociedade brasileira. Nesse contexto, é importante destacar que história também é discurso, pois passa pelas concepções do autor (quem a registra), e que pode subverter/enaltecer enunciados, os quais poderão ser tomados como "verdades" para determinado público, num determinado tempo e espaço. Bakhtin diz que "[...] os sentidos do passado, isto é, nascidos no diálogo dos séculos passados, podem jamais ser estáveis (concluídos, acabados de uma vez por todas): eles sempre irão mudar (renovando-se) no processo de desenvolvimento subsequente, futuro do diálogo." (BAKHTIN, 2011, p. 410).
} 
das relações étnico-raciais em contextos educacionais, em uma perspectiva dialógica?.

\section{No Navio: bagagens epistemológico-axiológicas}

Ao discorrermos sobre a proposição/implementação de um currículo, consideramos relevante problematizar algumas questões que podem se constituir como uma provocação para pensarmos a formação de professores de línguas e o compromisso ético de abordar as relações étnicoraciais de modo reflexivo.

Ao iniciarmos nossa discussão, partimos da afirmação de Hall (2003, p. $37)$.

A raça é uma categoria discursiva e não uma categoria biológica. Isto é, ela é categoria organizadora daquelas formas de falar, daqueles sistemas de representação e práticas sociais (discursos) que utilizam um conjunto frouxo, frequentemente pouco específico, de diferenças em termos de características físicas e corporais, etc. como marcas simbólicas, a fim de diferenciar socialmente um grupo de outro.

Conceber a raça como uma categoria discursiva implica analisar os currículos, que tomam essa questão como um dos objetos para discussão, como um ato de linguagem, ou seja, como uma prática cultural, lugar de embates e produção de sentidos e significados, portanto, arena de construção identitária.

Nesse sentido, Carvalho e Castro (2017), discutindo as prescrições curriculares, à luz da teoria de Bakhtin, evidenciam que os princípios metodológico-axiológicos instaurados por esse arcabouço teórico, nos permitem inquirir acerca dos processos históricos que são constitutivos dessas proposições curriculares. Para os autores, uma base curricular deve considerar "ocasiões e circunstâncias em que dados enunciados foram incorporados por outros enunciados e, extemporaneamente, passaram a ser

\footnotetext{
9 "Aquilo que Bakhtin chama de relações dialógicas não remete ao diálogo face a face (como muitos acreditam), mas à dinâmica de múltiplas inter-relações responsivas entre posições socioavaliativas. Na interação vista pelo olhar bakhtiniano, não se trocam mensagens, mas se dialogizam axiologias" (FARACO, 2005, p. 219).
} 
citados em discursos posteriores". (136). Assim, é preciso problematizar questões, como "quem produz", "para quem produz", "o que produz", "o que se quer quando produz", "quais as relações de poder que estabelecem os conteúdos tomados como válidos", "quem estabelece o conhecimento a ser valorizado e ensinado, nas escolas, como verdadeiro".

Além disso, os autores supracitados consideram ser fundamental problematizar os sentidos da palavra "currículo", que de origem latina curriculum - era um substantivo derivado do verbo currere (correr), o que acenava para a ideia de mobilidade. Paradoxalmente, a ideia originária de "correr" foi apagada, em decorrência de os sentidos serem produzidos em uma perspectiva sócio histórica que influencia os modos de ver e de conceber as relações sociais. Para os autores, a concepção atual de currículo "é justamente o oposto. Alude à falta de mobilidade, ou seja, constitui um conceito que deixou de correr livremente por espaços sociais abertos para, em outra direção, restringir e aprisionar determinados saberes." (CARVALHO; CASTRO, 2017, p. 136).

Ao pensarmos a questão dos currículos em cursos de formação de professores de línguas, várias questões são emanadas e a depender dos pressupostos epistemológico-axiológicos, que fundamentam a proposta curricular, a constituição (inter)subjetiva dos futuros-professores pode ser mais ou ser menos crítica.

A partir do excerto do poema de Castro Alves, podemos compreender esse contexto. Chama atenção a quase tatilidade conferida pelo aspecto visual denotando movimento ao poema e o fato de que o leitor parece convidado a adentrar no navio como testemunha da violência. O texto implica o leitor e o mobiliza a uma resposta. Colocar-se no lugar do outro é, notadamente, reconhecer-se (no) outro e, nessa relação de alteridade, adquirir conhecimento de si e do outro. O poema, com suas escolhas lexicais, é organizado a partir de um sistema próprio de valores, no tempo e no espaço.

Como disse o filósofo Walter Benjamin, em sua quinta tese (1940), "o passado só se deixa fixar, como imagem que relampeja irreversivelmente, no 
momento em que é reconhecido" (BENJAMIN, 1987, p. 224), ou seja, revisar o passado significa retomá-lo em nosso tempo presente como um movimento dialético e é, nesse sentido, que escovar a história a contrapelo é fundamental, já que implica compreender, a partir do olhar do negro, com sua cultura, história e sociedade, os elementos que de certo modo acabaram por "apagar sua identidade".

Desse modo, não ver a cor significa não reconhecer o outro e, portanto, não reconhecer a si mesmo em sua alteridade, ou seja, em sua identidade. Logo, o "contrapelo' a que se referiu Benjamin, dialoga com o conceito de alteridade bakhtiniano.

Nesse âmbito, a alteridade nos parece ser um conceito basilar ao discutirmos sobre a implementação de um currículo que abrace as relações étnico-raciais. Para Bakhtin (201 1, p. 300),

\begin{abstract}
Uma visão de mundo, uma corrente, um ponto de vista, uma opinião sempre têm expressão verbalizada. Tudo isso é discurso do outro (em forma pessoal ou impessoal), e este não pode deixar de refletir-se no enunciado. O enunciado está voltado não só para seu objeto, mas também para os discursos dos outros sobre ele.
\end{abstract}

Essas trocas enunciativas evidenciam que as relações dialógicas são fundantes da constituição dos sujeitos e das intersubjetividades, dos modos de reação às tensões e lutas presentes nas interações. Nesse contexto, consideramos que a diversidade racial não deve ser concebida apenas sob o ponto de vista de um conteúdo didático de uma matriz curricular, pois demanda a construção de posicionamentos críticos e atenção aos modos de constituição dos discursos, e por consequência, dos sujeitos. Implicar a alteridade nessa discussão evoca ressignificar metodologias, instaurar novas construções discursivas e compreender a produção ideológica da realidade social. Alteridade pressupõe o entrecruzamento histórico, cultural e social. E não somente como componentes contextuais à constituição (inter)subjetiva dos sujeitos, mas porque, no espaço-tempo dos acontecimentos que congregam esses sujeitos e que são constituídos pela própria presença deles em interação, são, também, relacionais. 
No âmbito da alteridade, os sujeitos podem se deixar afetar de modo diferenciado frente às situações de racismo. Assim, é possível observarmos atitudes e comportamentos que vão desde a omissão (naturalização do racismo) até o posicionamento crítico (compromisso ético com as desigualdades raciais). Para Ferreira (2014, p. 250), é relevante ter "uma compreensão poderosa e complexa da forma como raça influencia as experiências sociais, econômicas, políticas e educacionais dos indivíduos e dos grupos". Essa perspectiva crítica possibilita o exercício docente mais crítico, mais notadamente, para a área da linguagem, que, de modo mais incisivo trabalha com discursos, sendo "responsável por educar cidadãos que sejam críticos e reflexivos sobre como o racismo está estruturado na sociedade. (FERREIRA, 2014, p. 250)

Complementando o exposto, Villarta-Neder, Ferreira e Ribeiro (2018) defendem

a posição de que os encaminhamentos didático-metodológicos adotados pelo professor, notadamente, estão assentados em suas referências, princípios, crenças e saberes, que advêm de suas experiências e de conhecimentos adquiridos ao longo de sua formação. Desse modo, se o professor possuir uma base epistemológica acerca das questões históricas e sociais relacionadas à dimensão racial, a exploração sobre essa temática poderá ser dimensionada em uma perspectiva crítico-reflexiva. Além disso, se o professor entender a produção discursiva como um vasto e complexo universo de interações orientadas sócio historicamente, poderá encaminhar metodologias de ensino que problematizem os processos de circulação de determinados sentidos e a construção de determinadas significações.

Desconstruir produções discursivas que naturalizam ou que subestimam as desigualdades raciais é uma tarefa de uma educação que se propõe a ser emancipatória. Assim, é o olhar exotópico10 que possibilita a compreensão ativa e produtiva de cenas enunciativas constituídas por discursos que podem favorecer a manutenção de ideologias de inferiorização da raça negra. Para Santos (2014, p. 80),

\footnotetext{
${ }^{10}$ Para Bakhtin há um lugar localizado fora do sujeito, mas que é o único a partir do qual o sujeito pode se ver por inteiro, com acabamento (ainda que provisório). Esse conceito (vnienakhodímost em russo) é traduzido por exotopia, distância, extralocalização, extrainventividade.
} 
O olhar do eu sobre o outro e o olhar do outro sobre o eu requerem um movimento de colocar-se no lugar do outro, ver o mundo sob o prisma do outro, voltar a seu próprio lugar e completar o horizonte do outro, processo fundamental na interação, pois o eu pode completar o enunciado do outro e encaminhar o acabamento concludente desse enunciado.

Essa arquitetura exotópica desvela que para a avaliação de discursos ou atitudes ou palavras - do presente ou do passado - demandam um entendimento de mundo de maneira refletida e refratada, considerando-se o tempo, o espaço e os sentidos neles subjacentes. Machado (2010) reitera que o espaço das relações dialógicas se define em função das interações em jogo no campo de visão e naquilo que o excede. Essa construção exotópica realiza-se pela ocupação do lugar de outro indivíduo de maneira axiológica.

De acordo com Garcia (2012, p. 33),

Somente uma postura dialógica orienta a consciência a enxergar na outra o seu valor pleno e igualmente importante. Ainda assim não é tudo. É necessário também um exercício de autoavaliação, de autocrítica para se posicionar de forma satisfatória. Isso é possivel através da cobrança exotópica. Com o olhar para si de fora de si, com a não coincidência do sujeito com ele mesmo, o indivíduo é solicitado a contemplar sua consciência, realizando um movimento de descentramento importante para a atividade crítica. Enfim, a cobrança exotópica demanda a criticidade e reflexão necessárias para que o indivíduo, a partir das relações dialógicas com o outro, com o mundo e consigo mesmo, possa se colocar de forma consciente nessa profusão de vozes contemporâneas. Dessa forma, o indivíduo reuniria condições necessárias para se constituir como um sujeito dialógico. O sujeito dialógico, portanto, seria aquele capaz de se posicionar nessa multiplicidade de vozes e consciências.

Essa citação nos fornece elementos importantes para pensarmos as relações dialógicas que ocorrem a partir das propostas curriculares. Para além do currículo formal ${ }^{11}$, tradicionalmente presente nas propostas pedagógicas, a consideração do currículo como um processo de formação

${ }^{11}$ O currículo formal é considerado como o conjunto de elementos que são organizados com fins de promoção de aprendizagens e que consta de um plano de ensino e aprendizagem: objetivos, conteúdos e atividades. 
de sujeitos, já que pode ser concebido como uma atividade de linguagem ${ }^{2}$, pode ensejar possibilidades de tomar a própria cultura como objeto de discussão. Nesse movimento exotópico, o estudante pode ter contato com outras perspectivas e possa assumir novos posicionamentos.

Sinteticamente, esse viés sustenta a noção de compreensão responsiva ativa, um outro conceito bakhtiniano importante para a discussão sobre o currículo. O sujeito se constitui através de interações em que se perpassam vozes sociais constantemente em múltiplas inter-relações dialógicas. E é nesse movimento, por meio da compreensão responsiva (processo de construção de sentido em que o interlocutor tem participação ativa), que o sujeito se constitui.

Para Volóchinov (2017, p. 232),

Toda verdadeira compreensão é ativa e possui um embrião de resposta. Apenas a compreensão ativa é capaz de dominar o tema, pois um processo de formação só pode ser apreendido com a ajuda de outros processos também de formação. Compreender um enunciado alheio significa orientar-se em relação a ele, encontrar para ele um lugar devido no contexto correspondente. Em cada palavra de um enunciado compreendido, acrescentamos como que uma camada de nossas palavras responsivas. Quanto maior o seu número, quanto mais essenciais elas forem, tanto mais profunda e essencial será a compreensão. [..] Toda compreensão é dialógica.

Nesse contexto, é possível entendermos que todos os sujeitos interlocutores integram a constituição do texto (sempre enquanto enunciado), pois o falante é visto como alguém que espera uma réplica por parte do leitor/ouvinte e o ouvinte como alguém que, mesmo por ouvir e por compreender, já enuncia uma atividade responsiva ativa. A decisão de explicitar ou não essa compreensão e essa escuta resulta em um posicionamento (postupok) - um ato responsável - que dialoga com o

12 Corazza (2001, p. 9-10) assevera que, por meio do currículo, podemos "identificar significantes, significados, sons, imagens, conceitos, falas, língua, posições discursivas, representações, metáforas, metonímias, ironias, invenções, fluxos, cortes [...]" A autora considera que a natureza "linguageira" do currículo possibilita reconhecer a natureza de sua discursividade, que é histórica e socialmente construída. Permite também perceber "que seu discurso fornece apenas uma das tantas maneiras de formular o mundo, de interpretar o mundo, e de atribuir-lhe sentidos." Um currículo, nessa perspectiva, "é uma prática social, que se corporifica em instituições, saberes, normas, relações, valores, modos de ser sujeito".

Revista Exitus, Santarém/PA, Vol. 9, № 4, p. 176 - 203, Out/Dez 2019. 
posicionamento do falante. Assim, no âmbito das discussões sobre racismo, essa questão se sobreleva, pois os interlocutores podem assumir posturas diversas, que vão desde a omissão ao compromisso ético de respeito/recusa às desigualdades sociais ${ }^{13}$.

Nesse viés, atentar-se para os diferentes mecanismos que (co)participam do processo de produção dos discursos, que circulam na sociedade no que tange à desigualdade racial, constitui-se uma importante base epistemológica para (des)construir novos princípios axiológicos.

Ao tratarmos dessa questão, é relevante implicar outro conceito - ato responsável, que está intrinsecamente relacionado. Nesse sentido, Geraldi (2015, p. 85) destaca que

[...] responsabilidade abarca, contém, implica necessariamente a alteridade perante a qual o ato responsável é uma resposta. Somos cada um com o outro na irrecusável continuidade da história. Buscar eventos, nas singularidades, nas unicidades dos atos desta caminhada como se realizam as 'respostas responsáveis' é um modo de reencontrar os deslocamentos imperceptíveis na construção dos valores, dos sentidos que regem, mas que se fazem e se desfazem na existência.

Articulando a discussão sobre ato responsável à formação docente para o trabalho com as relações étnico-raciais, é relevante pontuar que incursões históricas são necessárias, mas também a implicação dos princípios axiológicos que constituem esse processo formativo e a questão da diversidade racial. Discorrendo sobre a noção de ato responsável, Sobral (2008) afirma que todo ato implica um agente - sujeitos concretos que realizam atos e essa questão apresenta duas implicações:

13 Para Stafuzza e Oliveira (2014), a classe dominante, no/sobre o tempo-espaço da colonização, (re)velam algumas práticas e discursos: i) o colonizador desumanizar o negro retirando-lhe sua língua, seu nome, sua religião e sua cultura africana, substituindo-a pela cultura cristã portuguesa; ii) o colonizador considerar o negro um mero instrumento de trabalho nas grandes fazendas e na mineração, sendo comparado com animais (macaco, mula), com a justificativa de que os negros não possuíam almas, por isso não sentiam o peso da escravidão; iii) a cristalização da ideia de que seria melhor que os negros fossem escravos, pois a escravidão os tirariam das mazelas em que viviam; iv) a cristalização da ideia que os negros não eram maltratados e sim civilizados e, ainda, pós-escravidão, recorrer ao discurso que os negros não eram capazes de serem trabalhadores livres. [...] Essas práticas e discursos equivalem aos diferentes modos de como o mundo entra no campo de apreciação dos grupos sociais. 
(a) o agente age numa situação concreta organizada em torno de práticas sociais e históricas que limitam as possibilidades de atos e de formas de realização de atos e (b) essas circunstâncias específicas devem ser consideradas em todo entendimento de atos. As práticas sociais, vinculadas com as esferas de atividade, supõem necessariamente grupos humanos, e não sujeitos isolados. Supõem igualmente situações concretas e sujeitos concretos. Supõem ainda a intencionalidade do sujeito de realizar atos e sua realização concreta de acordo com formas aceitas de realização, mesmo nos casos em que uma sucessão de atos, seguindo essas normas, desemboca na alteração dessas mesmas normas (o aspecto estático-dinâmico de todo agir humano) (SOBRAL 2008, p. 228).

Conceber o currículo como uma proposta de efetivação de situações discursivas, de construção coletiva de conhecimentos, valores e atitudes, enfim, como uma prática de linguagem, pressupõe considerar as possibilidades de trocas interativas entre sujeitos/agentes em seus diferentes pontos de vista. Isso significa assumir, segundo Bakhtin, que compreender um objeto implica "[...] compreender meu dever em relação a ele (a atitude ou posição que devo tomar em relação a ele), isto é, compreendê-lo em relação a mim mesmo no Ser-evento único, e isso pressupõe minha participação responsável, e não uma abstração de mim mesmo." (BAKHTIN, 1993, p. 35).

O ato responsivo de uma proposta curricular que contemple questões relacionadas à raça e ao racismo evoca a compreensão das construções históricas de formação e de desenvolvimento das sociedades e dos pressupostos axiológicos que fundam as ações da contemporaneidade. Articular, dialeticamente, passado e presente, representa uma possibilidade de ressignificação do agir humano.

Aprofundando essa questão, Geraldi (2010, p. 140) pontua que o agir, nos pressupostos de uma compreensão ativa, impõe aos sujeitos a responsabilização pela compreensão construída nos processos de interação. Para o autor, essa responsabilidade é dupla no sentido de que ações que os atos de um sujeito desencadear no futuro (ações de outros e minhas) resultarão de uma compreensão que não se relaciona mais somente ao ato em si, mas também ao ato de que o ato de cada sujeito foi resposta. 
Diante do exposto, podemos considerar que, no campo das interações imanentes a cada ato enunciativo, são tecidos os sentidos e estabilizados significados partilhados. Reiteramos que é por meio de práticas de linguagem, orientadas por uma perspectiva dialógica, que é possivel desconstruir e desnaturalizar discursos racistas, delinear identidades e, de um modo mais geral, compreender a égide social, cultural e política.

Assim, é possível assegurar que as escolhas metodológicas podem influenciar uma percepção monológica e naturalizada das relações étnicoraciais. Ao considerar o currículo para além de uma prescrição institucionalizada, o foco pedagógico pode recair nos processos históricoculturais de formação da sociedade, o que reporta à pluralidade de pontos de vista e ao diálogo constitutivo dos diferentes discursos ideológicos já consolidados sobre os significados/sentidos acerca da raça e do racismo. Analisar esses discursos é propiciar tempos-espaços de questionamentos e tensionamentos, de atitudes responsivas ativas, de construção alteritária, que podem legitimar uma formação docente aberta para uma possibilidade outra de perceber o mundo, o outro e a si mesmo e de (re)significá-los.

\section{Provocações teórico-metodológicas para a uma discussão do/sobre currículo}

Para uma melhor compreensão dos princípios epistemológicoaxiológicos que fundamentam a nossa discussão, apresentaremos alguns excertos das respostas dos participantes do curso de extensão ofertado em um curso de formação de professores. O curso foi proposto, como uma proposta de atividade de extensão e envolveu 25 alunos do curso de graduação em Letras - modalidade licenciatura - e 3 professores de escolas públicas. O curso foi desenvolvido nos meses de novembro e dezembro de 2018 e janeiro de 2019 e teve como pressuposto básico uma abordagem plural, de implicação de sujeitos e da relação dialética entre discursos e saberes sobre as relações étnico-raciais.

A proposta do curso assumiu uma metodologia que valorizou as interações entre os participantes, ou seja, foi idealizado a partir de uma 
perspectiva de que as atividades seriam concebidas como provocações para a constituição de sujeitos-enunciadores e não como uma prescrição de atividades a serem cumpridas.

De acordo com Guimarães (2018, p. 34-35), epistemologicamente, um processo formativo deve implicar diferentes atores sociais, não apenas o professor e, deve romper fronteiras disciplinares e culturais. Além disso, o autor destaca a importância de se dialogar com os diferentes pontos de vista, valorizados nos meios acadêmicos ou situados às margens do mundo em uma perspectiva que abarque os atravessamentos das lógicas coloniais. Além disso, recomenda o questionamento dos cânones, seus modos de construção e de suas contribuições, transbordando os modos canonizados pela academia ocidentalizada e problematizando $O$ pensamento hegemônico, que nem sempre dialoga com os modos ético-estéticos múltiplos dos muitos povos que formam nossa cultura: "é preciso olhar para o terreiro e para a aldeia como espaços de produção de conhecimento que propõem outras estéticas, que se desdobram em outros tempos e espaços", (p. 35), de modo a ressignificar os modos de ser professor, valorizando "um processo de reflexão, de escolhas, de caminhos, em busca de uma pedagogia decolonial na Universidade, (auto) crítica de meu fazer/saber, que se faz em coletivo".(p.35).

Nesse contexto de questionamentos das estruturas disciplinares e da proposição de tarefas, problematizamos algumas situações de trocas interativas.

Não pretendemos aqui esgotar todas as potencialidades trazidas pelo corpus, mas proceder a um recorte de questões que consideramos relevantes para uma reflexão sobre o currículo voltado para uma educação antirracista. Nesse sentido, selecionamos duas atividades que consideramos relevantes para iluminar a proposição/ implementação de uma base curricular que insere as questões étnico-raciais como uma das temáticas a serem incorporadas no currículo relativo ao percurso formativo de professores. Ao concebermos a linguagem como um processo dialógico 
entre interlocutores, reconhecemos que ela se constitui e é constituída no/pelo contexto e pelos sujeitos envolvidos no acontecimento enunciativo.

Atividade: Relato

1) Relatar episódios de racismo: Produza um texto que narre uma situação (situações) de racismo (em qualquer espaço social), que pode $(m)$ ter sido vivenciada(s) por você ou por outra pessoa. Socialize o texto produzido.

2) Considerando as situações de racismo (narradas ou lidas no fórum anterior), responda: Por que essas situações acontecem?

3) Considerando as narrativas produzidas ou lidas, no fórum anterior, discuta: Que estratégias podem ser implementadas para a minimização de episódios de racismo?

A instalação de práticas formativas, destinadas ao professor de línguas, precisa evidenciar que o trabalho com a linguagem comporta, além dos conteúdos linguístico-textuais, dimensões discursivas, as quais precisam ser valorizadas no processo de ensino-aprendizagem. Em uma abordagem discursiva, o processo de compreender é dimensionado na perspectiva de uma resposta a uma demanda, a um dizer, um fazer do outro. Assim, compreender não se circunscreve ao ato de um sujeito se posicionar discursivamente sobre uma determinada questão (tal como responder questões de interpretação do poema Navio Negreiro, por exemplo), mas se apropriar dos discursos do outro para a constituição da enunciação, e, enfim, contra argumentar (tal como analisar a dimensão espaço-temporal em que o poema foi produzido, por exemplo).

Na atividade proposta, partimos de uma solicitação aos participantes para que relatassem uma situação de racismo. Além da relevância de o relato servir à percepção de que atitudes e comportamentos que evidenciam preconceitos e discriminações estão presentes em nosso cotidiano e precisam ser enfrentados, foi possível problematizar o papel do sujeito-professor. Para tal, partimos do pressuposto que uma discussão sobre os princípios discursivos que fundamentam a proposição/implementação de um currículo que aborde as questões étnico-raciais poderia trazer subsídios 
epistemológico-axiológicos relevantes para a formação reflexiva de professores.

A discussão sobre os relatos possibilitou a compreensão de que as trocas intersubjetivas são necessárias para uma possível ressignificação de valores, crenças e posturas que são problematizados no percurso formativo.

De acordo com Silva (2002, p. 14), a escola é uma importante agência de letramento racial, que pode determinar repercussões positivas ou negativas para a formação de alunos, de modo mais estrito, de alunos negros.

As manifestações da discriminação racial na escola conformam um quadro de agressões materiais ou simbólicas, de caráter não apenas físico e/ou moral, mas também psíquico, em termos de sofrimento mental, com consequências ainda não satisfatoriamente diagnosticadas, visto que incidem cotidianamente sobre o alunado negro, alcançando-o já em tenra idade. Partimos, portanto, da constatação de que a escola é, concretamente, um preditor de destinos profissionais, ocupacionais e de trajetórias de vida, segundo a raça-cor do alunado, repercutindo sobre sua vida social e intrapsíquica, podendo ser um desencadeador ou um entrave ao seu pleno desenvolvimento (SILVA, 2002 p. 14).

Podemos esclarecer essa questão, a partir de um excerto de um relato de uma participante do curso de extensão realizado. No excerto a seguir, uma das participantes reflete sobre o racismo no cotidiano social:

Esta experiência ocorreu com minha mãe. Mulher, negra e casada com um homem branco (o que já incomodou muitas pessoas da família do meu pai). Por várias vezes na escola, eu escutava alguns comentários sobre ela, mas, especificamente, em um dia uma colega me chamou e disse que tinha algo muito sério para me falar. Ela questionou o fato de meu pai ter se casado com minha mãe, levando em conta que ela é "daquela cor né" (palavras da infeliz). Como se não bastasse, ela disse que eu fui adotada, que "aquela mulher jamais poderia ser minha mãe, porque não éramos da mesma cor". Na época, ainda criança, eu não compreendi muito bem do que se tratava, mas relatei para a minha mãe e, consequentemente, a direção da escola foi comunicada. Alegaram que era NORMAL esse tipo de atitude naquela idade, e que minha mãe não poderia dar bola para esse tipo de briga de criança, tanto a direção da escola quanto os pais da colega riram da situação, pois "havia assuntos mais importantes para serem tratados" (destaque da participante) 
Constatamos que produzir/ler episódios como esse, em contexto de formação de professores, nos permite problematizar as situações de produção, circulação e recepção dos textos/discursos e nos dá sinalizações de como os discursos e atitudes racistas se impõem e se perpetuam.

Dessa perspectiva, tratar dessas questões em sala de aula é mais do que colocar em contraponto palavras. Para Bakhtin/Volóchinov

na realidade, não são palavras o que pronunciamos ou escutamos, mas verdades ou mentiras, coisas boas ou más, importantes ou triviais, agradáveis ou desagradáveis, etc. A palavra está sempre carregada de um conteúdo ou de um sentido ideológico ou vivencial. É assim que compreendemos as palavras e somente reagimos àquelas que despertam em nós ressonâncias ideológicas ou concernentes à vida (BAKHTIN/VOLÓCHINOV, 1988, p. 95).

Nessa direção, não nos parece ser suficiente abordar a temática do racismo em datas comemorativas ou como um tópico de um ementário, é preciso implicar os sujeitos para uma (re)significação discursiva para a mobilização para a assunção de um posicionamento crítico por parte do futuro-professor.

Assim, ao analisarmos a inserção das questões sobre raça/racismo em um contexto uma data comemorativa, podemos ignorar o fato de que essa data representa um marco inaugural de um passado histórico e que estabelece um diálogo com o contexto social da contemporaneidade e com a temporalidade dos sujeitos implicados.

Essa problematização demanda do futuro-professor uma atitude responsiva ativa, que mobiliza os sujeitos para uma inserção no mundo, como um ato responsável, que envolve a singularidade sem álibi do nosso existir-evento ${ }^{14}$. Para Zsundy $(2014$, p. 16)

Quanto mais desenvolvida a consciência de que nenhuma realidade é assim mesmo (FREIRE, 1997), ou seja, de que os enunciados mais refratam do que retratam a realidade

\footnotetext{
14 Viver significa "ocupar uma posição de valores em cada um dos aspectos da vida, significa ser numa ótica axiológica." (BAKHTIN, 2000, p. 202). Separada da responsabilidade, a vida não pode ter uma filosofia; ela seria, por princípio, fortuita e privada de fundamentos" (BAKHTIN, 2010, p.117).
} 
(VOLOSHINOV, 1929/1999), maiores as possibilidades de se inserir no mundo para transformá-lo.

Esse posicionamento epistemológico articula-se à formação de professores, uma vez que o exercício docente não deve centrar-se em uma abordagem que atribua primazia às teorizações e seus efeitos práticos, mas "ao existir como evento moral, em seu cumprir-se real - à razão prática". Isso somente se efetiva por meio de uma atitude responsiva ativa, (BAKHTIN, 2010, p. 58).

Segundo Zsundy (2014) a formação/atuação de professores em uma perspectiva do educar responsável e responsivamente abarca dois eixos: uma educação responsável pode fornecer subsídios e estratégias para a compreensão, o engajamento e a eventual transformação das práticas sociais. Assim, as atividades e projetos pedagógicos podem extrapolar a materialidade dos textos trabalhados em sala de aula, para situá-los como textos-enunciados, em uma perspectiva histórica e ideológica, analisando os discursos, tanto do ponto de vista do conteúdo, quanto do ponto de vista dos tipos e formas de discurso por meio dos quais os diferentes temas tomam forma, são comentados, se realizam, são experimentados, são pensados etc.

No caso em pauta, a autora do relato faz escolhas lexicais e apresenta destaques no texto, evidenciando uma posição de sujeito, dentro de uma relação intersubjetiva, constituindo-se com, por e para outro sujeito, na unidade do acontecimento. Implicar o sujeito no processo de ensinoaprendizagem pode ser uma estratégia para a formação de professores reflexivos, que, ao perceber e compreender os textos, "ocupa simultaneamente em relação a ele uma ativa posição responsiva: concorda ou discorda dele (total ou parcialmente), completa-o, aplica-o prepara-se para usá-lo, etc.;" (BAKHTIN, 2011, p.271). Ao utilizar a palavra "normal" em caixa alta e a frase "havia assuntos mais importantes para serem tratados", entre aspas, a participante evidencia a sua discordância ao que foi dito e assume uma posição enunciativa acerca da relevância de se abordar temáticas como raça/racismo em espaços escolares. 
Para além dessa consideração, as respostas aos dois questionamentos solicitados a partir do relato também merecem um comentário.

a) Por que essas situações acontecem?

\begin{abstract}
Lendo os relatos apresentados nesse curso, e levando em consideração as experiências que tive o desprazer de testemunhar, percebi que o racismo é velado, algumas vezes silencioso, uma "tradição" tão enraizada na cultura que os discursos são repassados muitas vezes sem forma intencional, outras em plena consciência. Essas coisas acontecem pois estamos imersos na cultura que carrega uma dívida histórica, e tentam calar a voz daqueles que sofrem. Acontece um episódio de racismo e é abafado, justificado com frases de "ah isso é normal", "É muito mimimi", "Só foi uma brincadeira" ... De certa forma, tais discursos legitimam o preconceito, o problema está na banalização da dor do outro, a crença de que somos superiores entre semelhantes, mas quando nos deslocamos da nossa zona de conforto e lidamos com mais empatia, esses discursos perdem força e nos desconstruímos dia após dia.

- racismo acontece por que deixamos que ele aconteça, banalizamos a questão de discriminação e nos silenciamos. O desafio está na questão: lute, se policie e busque repassar o respeito.
\end{abstract}

Ao serem levados a refletir sobre as motivações de per/insistência de situações de racismo, mesmo com os inúmeros avanços sociais alcançados pelas minorias sociais, os participantes fizeram discussões que forneceram questões bastante pertinentes para um contexto de formação de professores. O caso tomado para análise evidencia o sujeito não se constitui de modo individualizado, mas a partir das relações estabelecidas no espaço coletivo, nas relações de trabalho, nas cerimônias religiosas, nos vínculos de amizade, nas relações familiares, etc.

Em conformidade com Bakhtin (2011), os sujeitos são constituídos a partir das interações. Desse modo, os discursos que velam, que naturalizam ou que justificam historicamente o racismo são construídos em temposespaços, em um processo discursivamente construído. A construção de um enunciado leva em conta seus participantes, a situação social e a correlação sócio hierárquica entre os interlocutores do enunciado e isso implica questões axiológicas, ou seja, dimensões valorativas ${ }^{15}$. O espaço da sala de aula, os textos que nele circulam, os discursos que são (re)produzidos

15 A questão valorativa corresponde, na obra bakhtiniana, aos termos: apreciação, avaliação, acento de valor, valoração, julgamento de valor, valor apreciativo, orientação apreciativa, apreciação social, acento apreciativo etc. 
são determinantes para 0 processo de produção de sentidos. As experiências vivenciadas "podem tanto colaborar para a compreensão das questões sobre raça/etnia em sala de aula quanto podem reforçar experiências de preconceito." (FERREIRA, 2010).

Ao mencionar a questão do racismo como um fenômeno históricosocial ("tradição tão enraizada na cultura", "dívida histórica"), a participante evidencia um horizonte espacial e temporal que corresponde ao onde e quando do enunciado, em uma dialética entre passado/presente. Ao responder à questão proposta, a participante assume uma posição ativa responsiva, seja pela crítica aos enunciados cristalizados "ah isso é normal", "É muito mimimi", "Só foi uma brincadeira", seja pela prescrição deôntica: "lute, se policie e busque repassar o respeito." Essa atitude responsiva ativa, de acordo com Bakhtin (2011, p, 271), se realiza quando o sujeito ocupa em relação a discurso "uma ativa posição responsiva: concorda ou discorda dele (†otal ou parcialmente), completa-o, aplica-o, prepara-se para usá-lo, etc.".

Diante do exposto, podemos reiterar que desencadear uma posição ativa responsiva por parte de aluno (seja ele de qualquer nível de escolaridade) exige uma proposição curricular que conceba que a produção de conhecimentos, a construção de valores e a mobilização para atitudes éticas como um processo enunciativo.

b) Estratégias que podem ser implementadas para a minimização de episódios de racismo

Acredito que a abordagem nas escolas da temática negra (para além das datas comemorativas) pode ser uma das alternativas eficazes, considerando que esse é um ambiente onde se deve (na teoria, ao menos) instigar o pensamento crítico das pessoas. Ao entrar em contato com outras visões sobre o Brasil que não a eurocêntrica, visões estas que estejam atreladas à diversidade brasileira, os alunos poderiam ter acesso a variados pontos de vista, ou seja, variadas maneiras de entender uma história, e, assim, poderiam refletir sobre as problemáticas enraizadas na sociedade atual. Numa perspectiva mais individual, creio que intervir em episódios racistas (explícitos ou não), desconstruindo os preconceitos e as ideias que levam as pessoas a agir de determinada forma, é uma maneira de conscientizar as pessoas que não têm acesso à informação. Além disso, nós, pessoas não negras, deveríamos 
procurar ouvir relatos dessas pessoas, uma vez que não vivenciamos tal realidade e essa é uma forma de nos colocarmos no lugar do outro.

Assumir o lugar do outro é considerar as diferenças, que, por sua vez, "podem ser muito melhor compreendidas como experiências de alteridade, um estar sendo múltiplo, intraduzível e imprevisível no mundo" (SKLIAR, 2005, p. 59).

Inserir o racismo no currículo implica compreender como os nossos discursos, por mais que pareçam nossos, estão contaminados por outros discursos.

Assim, como aponta Bakhtin, não é a palavra em si que produz sentidos, mas a interação entre os sujeitos é que coloca em diálogo histórias de sentidos das palavras, enquanto enunciados que aludem ao que precede e suscitam o que sucede. Para o autor russo

\begin{abstract}
Os significados lexicográficos neutros das palavras da língua asseguram para ela a identidade e a compreensão mútua de todos os seus falantes, contudo o emprego das palavras na comunicação discursiva viva sempre é de índole individual-contextual. Por isso pode-se dizer que qualquer palavra existe para o falante em três aspectos: como palavra da língua neutra e não pertencente a ninguém; como palavra alheia dos outros, cheia de ecos de outros enunciados; e, por último, como a minha palavra, porque, uma vez que eu opero com ela em uma situação determinada, com uma intenção discursiva determinada, ela já está compenetrada da minha expressão. Nos dois aspectos finais, a palavra é expressiva, mas essa expressão, reiteramos, não pertence à própria palavra, ela nasce no ponto de contato da palavra com a realidade concreta do enunciado individual. Neste caso, a palavra atua como expressão de certa posição valorativa do homem individual (de alguém dotado de autoridade, do escritor, do cientista, pai, mãe, amigo, mestre etc.) como abreviatura do enunciado (BAKHTIN, 2011, p. 294).
\end{abstract}

Pensar nessa questão, nos impõe a pensar o papel da escola e, de modo especial, do professor. Além disso, implica perceber que os textos propostos para discussão, tal como o excerto do Navio Negreiro, que foi ponto de partida para nossa discussão, evidenciam tipos diferenciados de interações, que são vivos e tensos.

De acordo com Munanga, 
Alguns dentre nós não receberam na sua educação e formação de cidadãos, de professores e educadores, o necessário preparo para lidar com o desafio que a problemática da convivência com a diversidade e as manifestações de discriminação dela resultadas colocam quotidianamente na nossa vida profissional. Essa falta de preparo, que devemos considerar como reflexo do nosso mito de democracia racial, compromete, sem dúvida, o objetivo fundamental da nossa missão no processo de formação dos futuros cidadãos responsáveis de amanhã. (MUNANGA 2005, p. 15),

Nesse contexto, ao pensarmos em uma organização curricular que efetivamente trate as relações étnico-raciais de modo a favorecer a transformação social, é necessário implicar os processos de produção, de circulação e de recepção dos textos enquanto enunciados/discursos, nas dimensões de "quem produz", "para quem produz", "o que produz", "o que se quer quando produz". Problematizar essas questões à luz de Bakhtin nos impele a discutir momentos intrínsecos às relações sociais.

Levar em consideração essas instâncias implica deter a atenção no conceito bakhtiniano de arquitetônica:

Estes momentos fundamentais são: eu-para-mim, o outropara-mim, e eu-para-o-outro; todos os valores da vida real e da cultura se dispõem ao redor destes pontos arquitetônicos fundamentais do mundo real do ato: valores científicos, estéticos, políticos (incluindo também os éticos e sociais) e finalmente religiosos (BAKHTIN, 2010, p. 114).

O conceito de arquitetônica, para Bakhtin concebe essa inter-relação, essa constituição intersubjetiva que instaura os sujeitos, produz, faz circular os sentidos, recepciona essa palavra que, feito camaleão, vai sendo outra, passando de alheia para alheia/minha e, finalmente, para o espaço e tempo do sujeito como acontecimento único de enunciar(-se) na/pela relação com ele mesmo, com o outro e com o mundo.

Pensar e discutir o racismo nessa perspectiva, enquanto uma das práticas de um currículo concebido como movimento, como construção, instiga a uma abordagem emancipatória. Ou, ao menos, à explicitação das posições, dos atos responsáveis de quem o pratica, de quem se submete 
servilmente, ou ainda, ao contrário, de quem se opõe, se indigna e se contrapõe.

\section{CONSIDERAÇÕES FINAIS}

Neste artigo, tecemos considerações sobre os pressupostos epistemológico-axiológicos que fundamentam uma concepção de currículo para além do conjunto de conteúdo, disciplinas e atividades. Nessa perspectiva, buscamos articular a nossa discussão com o referencial teórico bakhtiniano, que empresta relevantes contribuições para pensarmos um percurso formativo que implique sujeitos e suas interações.

Abordar as relações étnico-raciais sob o ponto de vista de um conteúdo disciplinar ou de uma temática a ser trabalhada em uma data comemorativa não é suficiente para a constituição de sujeitos responsivos, que enfrentam, de modo ético e político, os problemas, desafios e embates que surgem a partir das/nas práticas pedagógicas.

Nessa perspectiva, a discussão aqui empreendida, procurou evidenciar que somente a determinação legal e a inserção da temática História e Cultura Afro-Brasileira não asseguram a minimização de preconceitos e a desconstrução de discursos racistas, nem são capazes de promover mudanças nas práticas sociais.

Conforme demonstrado ao longo deste artigo, uma abordagem discursiva dos currículos pode favorecer o deslocamento de concepções relacionadas às práticas de ensino, promovendo o enfrentamento do racismo velado - recorrente nas escolas e na sociedade. Formar um professor de línguas, portanto, permite que o processo de construção intersubjetiva do currículo seja, também, um espaço de posicionamentos críticos e responsáveis sobre as relações étnico-raciais e constitua um diálogo entre acontecimentos pedagógicos reflexivos e eticamente compromissados. 


\section{REFERÊNCIAS}

BRASIL. Diretrizes Curriculares Nacionais para a Educação das Relações Étnico-raciais e para o Ensino de História e Cultura Afro-brasileira e Africana. Disponível <http://www.sinpro.org.br/arquivos/afro/diretrizes_relacoes_etnicoraciais.pdf>. Acesso 20 jun. 2018.

BRASIL. Lei n. 10.639, de 9 de janeiro de 2003. Disponível http://www.planalto.gov.br/CCivil_03/leis/2003/L10.639.htm Acesso 20 jun. 2018.

BAKHTIN, M. M. (1926). Para uma filosofia do Ato. Trad. exclusiva para uso didático e acadêmico de Carlos Alberto Faraco e Cristóvão Tezza de Toward a Philosophy of the Act. Tradução do russo por Vladímir Liupanov. Austin: University of Texas Press, 1993.

BAKHTIN, M. Para uma filosofia do ato responsável. Trad. Valdemir Miotello \& Carlos Alberto Faraco. São Carlos: Pedro \& João Editores, 2010.

BAKHTIN, M. M. Estética da criação verbal. Trad. da versão francesa por Maria Ermantina Galvão G. Pereira. 3.ed. São Paulo: WMF Martins Fontes, 2000.

BAKHTIN, M. M. Estética da criação verbal. Trad. Paulo Bezerra. 6.ed. São Paulo: WMF Martins Fontes, 2011.

BENJAMIN, W. Magia e técnica, arte e política. Obras Escolhidas. Vol. 1. 3.ed. São Paulo: Editora Braziliense, 1987.

CARVALHO, I. B. de; CASTRO, A. de C. Currículo, racismo e o ensino de língua portuguesa: as relações étnico-raciais na educação e na sociedade. Educ. Soc., Campinas, v. 38, n. 138, p. 133-151, jan. 2017. Disponível em: < http://www.scielo.br/scielo.php?script=sci_arttext\&pid=s010173302017000100133>. Acesso 22 fev. 2019.

CORAZZA, S. M. O que quer um currículo?: pesquisas pós-críticas em educação. Petrópolis: Vozes, 2001.

FARACO, C. A. Interação e linguagem: balanço e perspectivas. Calidoscópio, v. 3, n. 3, p. 214-221, set./dez.2005. Disponível em: <http://www.unisinos.br/publicacoes_cientificas/images/stories/pdfs_calidosc opio/vol3n3/art08_faraco.pdf>. Acesso em: ago. 2010.

GARCIA, D. B. Por uma Pedagogia da Autonomia: Bakhtin, Paulo Freire e a formação de leitores autorais. 2012. Dissertação (Mestrado em Educação) Universidade de São Paulo, São Paulo, 2012. 
GERALDI, J. W. A aula como acontecimento. São Carlos: Pedro \& João Editores, 2010.

GERALDI, J. W. Ancoragens: estudos bakhtinianos. 2. ed. São Carlos: Pedro \&João Editores, 2015.

FERREIRA, A. J. Teoria racial crítica e letramento racial crítico: Narrativas e contranarrativas de identidade racial de professores de línguas. Revista da ABPN, v. 6, n. 14, p. 236-263, jul. - out. 2014.

HALL, S. Da diáspora: identidades e mediações culturais. Belo Horizonte: Editora da UFMG, 2003.

MACHADO, I. A questão espaço temporal em Bakhtin: cronotopia e exotopia. In: PAULA, L. de; STAFUZZA, G. B. (orgs.). Círculo de Bakhtin: teoria inclassificável. Campinas, SP: Mercado das Letras, 2010.

ROSA, D. C.; COSTA-HÜBES, T. da C. A produção textual escrita como atividade de interação. In: COSTA-HÜBES, T. da C. (Org.). Práticas sociais de linguagem: reflexões sobre oralidade, leitura e escrita no ensino. Campinas, SP: Mercado de Letras, 2015.p.143-176.

SANTOS, J. O. C.. Uma discussão sobre a produção de sentidos na leitura: entre Bakhtin e Vygostsky. Leitura: Teoria \& Prática, Campinas, v.32, n.62, p.75-86, jun. 2014. Disponível em: <https://ltp.emnuvens.com.br/ltp/article/view/241/140>. Acesso em 10 jan. 2019.

SKLIAR, C. A questão e a obsessão pelo outro em educação. In: GARCIA, R. L.; ZACCUR, E.; GIAMBIAGI, I. (Orgs). Cotidiano: diálogos sobre diálogos. Rio de Janeiro: DP\&A, 2005. p. 49-62.

STAFUZZA, G. B.; OLIVEIRA, B. Narrativa de vida na produção artística de Emicida: a voz marginal em análise. In: MACHADO, I. L.; MELO, M. S. de S. M. (Org.). Estudos sobre narrativas em diferentes materialidades discursivas na visão da Análise do Discurso. Belo Horizonte: Núcleo de Análise do Discurso: FALE-UFMG, 2016, v. 1, p. 89-120.

SOBRAL, A. O Ato "Responsível", ou Ato Ético, em Bakhtin, e a Centralidade do Agente. Signum: Estudos Linguísticos. Londrina, v. 11, n. 1, p. 219-235, jul. 2008. Disponível em:

<http://www.vel.br/revistas/vel/index.php/signum/article/view/3092/2625>. Acesso em 10 jan. 2019.

VILLARTA-NEDER, M. A.; FERREIRA, H. M.; RIBEIRO, E. A. Letramento racial crítico e a constituição de subjetividades: desafios para a formação de 
professores de línguas. In: LIANDA, S. (Org.). O que pode a Linguística? . Alagoinhas, BA: Bordô-Grená, 2018, v. 1, p. 25-45.

VOLÓCHINOV, V. N. Marxismo e filosofia da linguagem. Trad. Sheila Grillo; Ekaterina V. Américo. São Paulo: Editora 34, 2017.

Recebido em: 28 de fevereiro de 2019 Aprovado em: 12 de agosto de 2019 